Available from: http://www.janaushadhi.gov.in/about_jan_aushadhi. html.

14. Chauhan V, Galwankar S, Arquilla B, Garg M, Somma SD, El-Menyar A,
Krishnan V, Gerber J, Holland R, Stawicki SP. Novel coronavirus (Covid-19): Leveraging telemedicine to optimize care while minimizing exposures and viral transmission. J Emerg Trauma Shock 2020;13:20-4.

\title{
Alcohol withdrawal management during the Covid-19 lockdown in Kerala
}

\section{RAVI PRASAD VARMA}

\begin{abstract}
The lockdown declared to prevent the spread of Covid-19 in India created unforeseen problems, including severe alcohol withdrawal symptoms and the need to manage them. The state of Kerala in India saw suicide deaths by six affected individuals, prompting the state government to instruct government doctors to prescribe alcohol to addicts. The local medical association approached the courts against this. These events raise interesting ethical issues discussed here.
\end{abstract}

Keywords: alcohol withdrawal, prescribing alcohol, Covid-19, ethics of alcohol prescription.

Alcohol is often considered a social evil, a poison which is bad for your health. So what prompted the government of Kerala to instruct doctors to prescribe alcohol to those suffering from its withdrawal? It began with the total lockdown of almost all non-essential services including liquor stores, against the threatening surge of Covid-19. The declaration was sudden and left everyone in the lurch, tipplers included. Kerala started witnessing a small wave of suicides attributed to alcohol withdrawal, with six such deaths as against two attributed to Covid-19, as on April 1, 2020 (1). In response, the concerned State authorities issued an order directing those with alcohol withdrawal symptoms to approach doctors at government hospitals for "passes" which would help them procure alcohol (2). The order immediately met with resistance from doctors. Leading professional medical organisations promptly obtained a stay from the Kerala High Court against the order (3). The predicament of those with alcohol withdrawal symptoms, the state's attempt to offer relief, and the doctors' unobliging rejoinder raise interesting ethical questions.

Persons who drink alcohol in considerable amounts over a long period of time are likely to become "dependent" on alcohol. This means that they develop some physical or mental reactions if they stop drinking. Some may experience only minor symptoms like shaking hands, headache, nausea and vomiting. In others these symptoms can be severe, resulting

Author: Ravi Prasad Varma (rpvarma@sctimst.ac.in), Associate Professor, Achutha Menon Centre for Health Science Studies, Sree Chitra Tirunal Institute for Medical Sciences and Technology, Trivandrum.

To cite: Varma RP. Alcohol withdrawal management during the COVID-19 lockdown in Kerala. Indian J Med Ethics. 2020 Apr-Jun; 5(2) NS: 105-6. DOI:10.20529/JJME.2020.042.

() Indian Journal of Medical Ethics 2020 in seizures or delirium tremens with high fever, high blood pressure, confusion, and hallucinations, and may even be fatal. The reported suicides of young persons testify to the gravity of these people's suffering under the current lockdown.

What are the rights of such habitual users of this statesanctioned (albeit controlled) substance under a lockdown? The government's response to the issue clearly indicates the State's acceptance of its responsibility for the problem and this aspect is commendable. The relationship of a state to alcohol is determined by historical and contemporary values around alcohol use in society. Alcohol is often a masculine motif and societies with strong patriarchal mores may add impetus to the state's position on alcohol. Another important aspect is the economics of the production, distribution and consumption of the substance. Stringent control measures may lead to illicit liquor production and consumption with disastrous health consequences. Thus, many governments support controlled availability of alcohol, aiming for a judicious balance between use and abuse.

Was it right on the part of the medical professionals, especially those employed by the state, to refuse to "prescribe" passes for persons with symptoms of alcohol withdrawal? Alcohol can cause severe medical illness - most medical students encounter the big belly of alcoholic liver disease early on in their careers. Medical lexicons are populated with many alcohol related diseases - alcoholic polyneuropathy, alcoholic myopathy, alcoholic cardiomyopathy, foetal alcohol syndrome and several more. It is easy to understand the doctors' opposition to this state order given the overall ethos of the profession in this regard. Additionally, the order has been interpreted as impinging on the right of medical practitioner to determine the contents of a prescription, given that there are effective treatments for symptoms of alcohol withdrawal. Doctors are also working in a situation where optional medical consultations including vaccinations are heavily restricted; and a call for alcohol prescriptions at such a time does raise a morally loaded question for many doctors.

Clearly, there is no simple answer to this dilemma. Should we let those in withdrawal pay the price in the interest of the greater good - prevention of rapid surge or better mitigation of the Covid-19 outbreak? They are after all part of the larger societal phenomenon. Will it be possible for the state or the health system to make the necessary treatments available where it is needed at a time like this? Such situations may test the harmony between various stakeholders at the forefront 
of the Covid-19 control measures. Stakeholders need to be conscious of differing positions emerging during such sweeping public health measures, and be able to reconcile such differences quickly so that they may continue to work as a team.

Note: The views and thoughts expressed in this letter are solely those of the author and do not in any way represent those of AMCHSS, SCTIMST, Trivandrum or any other group.

\section{References}

1. Jayakumar PB. Alcohol non-availability kills more than coronavirus in Kerala; foreign liquor served as 'medicine'. Businesstoday.com. 2020
Apr 1[cited 2020 Apr 13]. Available from: https://www.busiesstoday. in/current/economy-politics/alcohol-non-availability-kills-more-thancoronavirus-in-kerala-foreign-liquor-served-as-medicine/story/399716. html

2. SNS Web. Kerala govt issues passes for tipplers with 'withdrawal symptoms' amid coronavirus lockdown. Statesman. 2020 Mar 31[cited $2020 \mathrm{Apr}$ 13]. Available from: https://www.thestatesman.com/india/ kerala-govt-issues-passes-for-tipplers-with-withdrawal-symptomsamid-coronavirus-lockdown-1502872199.html

3. Livelaw News Network. Recipe for disaster:Kerala HC stays govt decision to supply liquor on doctor certifying alcohol withdrawal syndrome [read order]. Livelaw.in. 2020 Apr 2[cited 2020 Apr 13]. Available from: https://www.livelaw.in/top-stories/kerala-hc-stays-govt-decision-tosupply-liquor-to-persons-on-doctor-certifying-alcohol-withdrawalsyndrome- 154680 